\title{
A REPRODUÇÃO SOCIOECONÔMICA NA AGRICULTURA FAMILIAR: UMA ANÁLISE DA PECUÁRIA EXTENSIVA NA CAPELA DO CARAVÁGIO-RS
}

\author{
SOCIOECONOMIC REPRODUCTION IN FAMILY \\ FARMING: AN ANALYSIS OF EXTENSIVE LIVESTOCK IN \\ CAPELA DO CARAVÁGIO-RS
}

\author{
Filipe Augusto Xavier Lima \\ Universidade Federal de Santa Maria - Santa Maria - RS - Brasil \\ Gustavo Daniel Benítez Castro \\ Universidad de La República - Montevideo - Montevideo - Uruguai
}

Rodrigo Gisler Maciel

Universidade Federal do Pampa/Campus Santana do Livramento - Santana do Livramento - RS - Brasil

Pedro Selvino Neumann

Universidade Federal de Santa Maria - Santa Maria - RS - Brasil

\begin{abstract}
Resumo: Este estudo teve como objetivo elaborar um diagnóstico dos sistemas de produção da zona homogênea da Capela do Caravágio, Distrito de Coxilha Grande, município de Vacaria/RS, com foco em uma análise econômica de algumas de suas unidades de produção agropecuária (UPAs). Para tanto, foi utilizada a metodologia de Análise de Sistemas Agrários, reconhecida como um importante instrumento que permite perceber as transformações históricas e a diferenciação geográfica das agriculturas. Primeiramente, fez-se uma análise geral da região, por meio do tratamento de dados secundários, leituras de paisagens e entrevistas com informantes qualificados. Em seguida, foram caracterizadas as tipologias de produtores e seus sistemas de produção e, por último, foram realizadas análises econômicas dos sistemas de produção. Como resultado, pôde-se verificar o histórico da região vinculado à produção pecuária, que foi sendo substituída, nos últimos anos, pela produção de grãos e pela fruticultura. Porém, manteve-se o sistema pecuário em regiões onde os produtores não têm condições de se inserir na dinâmica produtiva dos grãos e das frutas. As análises das UPAs apontam uma grande disparidade nos três
\end{abstract}


sistemas analisados, tanto em termos de produtividade técnica como de resultados econômicos. Além disso, a dependência de rendas não agrícolas em algumas UPAs, assim como a dificuldade em manter os membros das famílias no campo, indica a necessidade de maior área para tornar viáveis os sistemas de pecuária extensiva da região.

Palavras-chave: Agricultores Familiares. Desenvolvimento Rural. Sistemas Agrários.

Abstract: This study aimed to make a diagnosis of production systems of homogeneous area of the Capela do Caravagio, District of Coxilha Grande, municipality of Vacaria/RS, with a focus on a economic analysis of some of its agricultural production units. For this, we used the methodology Analysis Agrarian Systems, recognized as an important tool to understand the historical changes and geographical differentiation of agriculture. First, became a general analysis of the region, through the treatment of secondary data, readings of landscapes and interviews with qualified informants, then they were the types of producers and their production systems, and lastly, the economic analyzes were performed production systems. As a result, you can check the history of the region linked to livestock production, which was being replaced in recent years by the grain and the fruit, however, kept up the system in areas where livestock producers are unable to insert the productive dynamics of grains and fruits. Analyses of UPAs show a wide disparity in the three systems analyzed, both in terms of technical productivity as economic outcomes. Furthermore, dependence on non-agricultural incomes in some UPAs, as well as the difficulty in keeping family members in the field, indicates the need for greater surface to make feasible the extensive pasture systems in the region.

Key-words: Family Farmers. Rural Development. Agrarian Systems.

\section{INTRODUÇÃO}

Este artigo tem como foco principal as alterações ocorridas na agricultura, que, ao longo do tempo, vem sofrendo modificações importantes, isto porque suas mais diversas formas e configurações resultam de complexas transformações da produção de alimentos, da geração de emprego e renda, das paisagens e particularidades sociais.

Sobre isso, em Mazoyer e Roudart (2010), encontra-se o seguinte esclarecimento: toda forma de agricultura, inicialmente, aparece como um objeto ecológico e econômico complexo, composto por várias categorias de estabelecimentos e tipologias de agricultores, que exploram diferentes tipos de solos e diversas espécies de plantas e de animais, configurando-se, por conseguinte, numa atividade produtiva de caráter multivariado. Além do mais, as formas de agriculturas observáveis variam conforme o tempo e o lugar de suas práticas, o que 
torna possível caracterizá-las em gêneros muito diferentes umas das outras. Desse modo, as transformações ocorridas na agricultura através do tempo e do espaço, fazem parte da evolução da história de toda e qualquer região do mundo (MAZOYER; ROUDART, 2010).

Para compreender a complexidade que envolve cada forma de agricultura e suas realidades, a teoria dos sistemas agrários é apontada por Mazoyer e Roudart (2010) como um importante instrumento que permite perceber as transformações históricas e a diferenciação geográfica das agriculturas. Assim, para um melhor entendimento sobre o que é um sistema agrário, antes de tudo, faz-se necessária uma distinção de como a agricultura é praticada, considerando também, aquilo que o observador pensa da agricultura, enquanto um objeto real de conhecimento. Para essa distinção das práticas agrícolas existentes, requer-se um conjunto de conhecimentos abstratos, mas que, trabalhados metodicamente, podem transformar-se em um verdadeiro objeto concebido, ou ainda, num objeto teórico de conhecimento e de reflexão (MAZOYER; ROUDART, 2010).

Ainda a respeito dos sistemas agrários, Mazoyer e Roudart (2010) afirmam que se trata da expressão teórica de um tipo de agricultura historicamente constituído e geograficamente localizado, composto de um ecossistema cultivado característico e de um sistema social produtivo definido. Os autores também observam que, ao se realizarem análises de sistemas agrários, deve-se considerar as atividades que the fornecem os meios de produção; a utilização que é feita de seus produtos pelas atividades e pelos consumidores; e a presença de outros sistemas agrários concorrentes, pois eles também contribuem para atender às necessidades da sociedade.

Após essa breve iniciação à dinâmica dos sistemas agrários, este artigo apresenta, como pesquisa empírica, a experiência dos agricultores familiares do Município de Vacaria - RS, particularizando o $6^{\circ}$ Distrito: Coxilha Grande. Esse Distrito apresenta duas zonas geográficas com características antagônicas: 1) Zona Oeste: onde predominam as produções de grãos (soja, milho), de maçã e a pecuária. Nessa região prevalecem as grandes propriedades, cujas áreas variam de 200 até 500 hectares (ha), e os produtores geralmente não encontram muitos problemas de infraestrutura para o desenvolvimento de suas atividades produtivas; e 2) Zona Leste: trata-se de uma região 
onde a pecuária tornou-se uma alternativa viável para muitos dos agricultores marginalizados pela dinâmica produtiva dos grãos e da maçã, devido à falta de infraestrutura e capital para investimentos. A Zona Leste inclui quatro comunidades: Capela Nossa Senhora da Aparecida, Capela do Caravágio, Capela São Sebastião Itacolomi e Capela São Pedro. Os estabelecimentos dessas comunidades são menores, variando entre 60 ha e 70 ha, destacando-se as atividades da pecuária, e as produções de grãos e uva e o reflorestamento (em menores escalas).

Entre as distintas realidades agrárias identificadas na Zona Leste do $6^{\circ}$ Distrito, procurou-se fazer um recorte da zona homogênea da Comunidade da Capela do Caravágio, pois apresenta particularidades no que diz respeito às características produtivas, socioeconômicas e culturais, quando comparada às outras áreas do Distrito de Coxilha Grande. Isso porque, além de apresentar a pecuária familiar como a principal atividade econômica dos agricultores, constatam-se, na comunidade, o predomínio de aposentados nos estabelecimentos; a redução da população nos últimos anos e uma expressiva presença masculina no meio rural; e a falta de infraestrura em serviços de transporte, saúde e educação.

A partir do caso da comunidade da Capela do Caravágio, formularam-se as seguintes questões para orientar a investigação: Qual o perfil dos agricultores familiares dessa microrregião? Como se deu a evolução dos seus sistemas de produção? Quais as principais características desses sistemas de produção atualmente, diante das modificações socioeconômicas e técnicas ocorridas nas UPAs do local? Assim, o presente trabalho tem como principal objetivo elaborar um diagnóstico dos sistemas de produção da zona homogênea da Comunidade da Capela do Caravágio, com foco em uma análise econômica de algumas de suas UPAs.

A importância deste estudo está na possibilidade de contribuir para a compreensão e aprofundamento teórico em torno dos aspectos relacionados à evolução dos sistemas agrários e dos sistemas de produção, bem como os avanços e dificuldades enfrentadas pelos agricultores familiares no que diz respeito às alterações em suas unidades de produção e na dinâmica da agricultura em determinada localidade. 


\section{OS SISTEMAS AGRÁRIOS, AS TIPOLOGIAS DE PRODUTORES E SEUS SISTEMAS DE PRODUÇÃO}

O desenvolvimento de um sistema agrário é resultado da dinâmica de seus estabelecimentos agrícolas. Considera-se que existe um desenvolvimento geral quando todos os tipos de estabelecimentos de um local progridem, adquirindo novos meios de produção, ampliando suas atividades e melhorando seu desempenho econômico e resultados. Por outro lado, o desenvolvimento pode ser considerado desigual quando certos estabelecimentos progridem num ritmo mais acelerado que outros, ou ainda, podem ser contraditórios, na medida em que alguns estabelecimentos encontram-se em situação de progresso, frente a outros que estão em crise e regridem drasticamente (MAZOYER; ROUDART, 2010).

Nesse sentido, a crise de um sistema agrário pode ser geral quando todos os tipos de estabelecimentos regridem e tendem a desaparecer com o tempo, mas, em certos casos, aqueles estabelecimentos agrícolas que se distanciam de tal crise e prosperam, podem adotar novos meios de produção, com novas práticas agrícolas, sistemas de cultivo e de criação, caracterizando-se como um novo ecossistema cultivado, gerando um novo sistema agrário (MAZOYER; ROUDART, 2010). Essa mudança é chamada por Mazoyer e Roudart (2010, p. 75) de revolução agrícola, pois, "ao longo do tempo podem nascer, desenvolver-se, declinar e suceder-se, em dada região do mundo, sistemas agrários que constituem etapas de uma série evolutiva característica daquela região."

Mazoyer (1987 apud GARCIA FILHO, 1999) destaca que um sistema agrário pode ser definido a partir das seguintes variáveis: 1) o meio cultivado, que compreende o meio original e suas transformações históricas; 2) os instrumentos de produção, com suas ferramentas, máquinas e materiais biológicos; 3 ) a força de trabalho social, tanto física como intelectual; 4) o modo de "artificialização" do meio, que resulta na reprodução e exploração do ecossistema cultivado; 5) a divisão social do trabalho, que permite a reprodução dos instrumentos de trabalho; 6) os excedentes agrícolas, que satisfazem as necessidades dos produtores e de outros grupos sociais; 7 ) as relações de troca, que 
regulam a repartição dos produtos do trabalho; e 8) o conjunto das ideias e das instituições, que permite assumir a reprodução social. Para Silva Neto e Basso (2005), um sistema agrário corresponde a um conjunto de conhecimentos elaborados a partir da observação, delimitação e análise de uma agricultura particular, cuja finalidade seria tornar a complexidade da agricultura mais perceptível, seguindo os objetivos específicos dos estudos ou intervenções para o desenvolvimento.

Silva Neto e Basso (2005) consideram que um sistema agrário é determinado por meio de um conjunto de critérios, ligados aos seus diferentes componentes ou subsistemas, distribuídos em dois grupos: o agroecossistema e o sistema social produtivo. O agroecossistema, ou ecossistema cultivado, corresponde à forma como se organizam os constituintes físicos, químicos e biológicos de um sistema agrário, ou seja, está ligado às transformações que os ecossistemas naturais sofrem para que grupos sociais possam obter produtos de seu interesse. $O$ sistema social produtivo, por sua vez, corresponde aos aspectos técnicos, econômicos e sociais de um sistema agrário, formado por um conjunto de unidades de produção, caracterizadas pela categoria social dos agricultores e pelos seus sistemas de produção (SILVA NETO; BASSO, 2005).

Ainda de acordo com os autores, a categoria social dos agricultores é definida pelas suas relações de produção, de propriedade e de troca com os demais agentes que atuam no meio rural, como, por exemplo, sindicatos rurais, associações ou cooperativas de produtores, institutos de pesquisa agropecuária e de extensão rural, e agentes de crédito. Desse modo, a categoria social à qual pertence um agricultor pode expressar, entre outras coisas, o seu acesso aos meios de produção disponíveis, bem como a divisão dos produtos gerados por suas atividades, resultando de um processo de acumulação condicionado pelo acesso à terra e pela origem da mão de obra e do capital (SILVA NETO; BASSO, 2005). A partir dessas considerações, argumenta-se que criar tipologias de agricultores torna-se necessário aos estudos sobre sistemas agrários, pois os produtores trabalham em condições ambientais e socioeconômicas distintas (acesso à terra, aos recursos naturais, à informação, aos serviços públicos, aos serviços de assistência técnica e extensão rural, aos mercados e ao crédito, etc.). 
São essas diferenças que geram evoluções distintas em níveis desiguais de capitalização e em critérios distintos de decisão e de otimização dos recursos disponíveis, ou seja, existem racionalidades socioeconômicas variadas entre os produtores, as quais condicionam suas escolhas no que se refere às culturas, às criações, às técnicas, às práticas agrícolas e econômicas (GARCIA FILHO, 1999). Em geral, os agricultores dispõem de uma base material diferenciada, evidenciada na qualidade e quantidade da terra e dos seus demais meios de produção. Além disso, estão integrados de forma distinta a um determinado meio agroecológico e socioeconômico, onde são construídas as relações de produção (LIMA et al., 1995).

Dentro dessa linha, Garcia Filho (1999) situa que em estudos da Organização das Nações Unidas para Agricultura e Alimentação (FAO), foram identificados três grandes tipos de unidades de produção: as unidades capitalistas, que dispõem de grande área e presença efetiva de trabalhadores assalariados; as unidades familiares, onde o trabalho é quase exclusivamente familiar, observando-se também diversidade nos níveis de capitalização e nos sistemas de produção; e as unidades patronais, cuja produção é realizada pela família e, ao mesmo tempo, por trabalhadores assalariados, sejam eles permanentes ou temporários. Em Souza et al. (1992) e Lima et al. (1995), encontra-se uma classificação voltada para o que se considerou representar o estágio de desenvolvimento da agropecuária brasileira e seu processo de diferenciação social e econômica no campo: latifúndio, empresa capitalista, empresa ou unidade familiar, unidade familiar camponesa e unidades neo-camponesas. Lima et al. (1995) entendem que os três últimos grupos são unidades de produção essencialmente distintas da empresa capitalista, na medida em que se inserem no meio físico e socioeconômico a partir de uma base material e social particular, onde buscam se reproduzir social e economicamente, realizando suas atividades basicamente por meio da mão de obra familiar.

Carneiro (1999), por sua vez, apresenta uma classificação direcionada para as unidades familiares agrícolas segundo os princípios que orientam sua reprodução social. Para a autora, as unidades familiares caracterizam-se pela íntima relação entre trabalho, terra e família, e a distinção entre elas estaria sobre a maneira particular de combinar: 
alternativas colocadas à disposição pelo contexto socioeconômico (extra familiares) e pelo campo de possibilidades (condições internas à família) específicos para realizarem suas escolhas e formularem suas estratégias particulares (CARNEIRO, 1999, p. 340).

Seguindo esse recorte, as categorias levantadas por Carneiro (1999) são: 1- A família agrícola de caráter empresarial, cuja lógica de reprodução social é determinada pela realização de uma produção orientada para o mercado, obedecendo à satisfação de índices de rentabilidade e de produtividade crescentes; 2- A família camponesa, cuja lógica está em manter a família em determinadas condições culturais e sociais, isto é, promover a manutenção da propriedade familiar e da exploração agrícola. A diversidade de estratégias individuais e familiares desse grupo deriva das fracas condições de produção: recorre-se a vários meios para manter a unidade de produção e garantir a reprodução social estruturalmente ameaçada; e 3- A família agrícola "rurbana", que não se orienta prioritariamente em função do lucro e da produtividade crescentes, mas é uma categoria que utiliza sua produção agrícola para a melhoria da qualidade de vida, sem deixar de considerar a realidade do mercado e, obviamente, a capacidade de retorno em termos de rendimento.

Nessa perspectiva, Dufumier (1990) enfatiza que é importante distinguir os diferentes tipos de agricultores de uma região, considerando seus interesses, os meios de produção disponíveis, as relações sociais em que trabalham e suas reações frente às evoluções tecnológicas da agricultura. Para o autor, esse é o papel que corresponde à tipologia de produtores agrícolas na análise e diagnóstico das realidades agrárias. Surge, então, a necessidade de delimitar os sistemas de produção passíveis de serem desenvolvidos por determinada categoria social dos agricultores, em um dado ecossistema (SILVA NETO; BASSO, 2005).

Os sistemas de produção correspondem à forma como os agricultores organizam as suas atividades no interior das suas propriedades, onde a diversidade das características ecológicas e sociais e a experiência particular acumulada por cada agricultor fazem com que jamais duas unidades de produção se apresentem de formas idênticas. 
Entretanto, é possível agrupar os sistemas de produção característicos de um sistema agrário a partir de certos condicionantes e problemas comuns, de forma a tornar a sua diversidade mais perceptível em um estudo (SILVA NETO; BASSO, 2005).

Garcia Filho (1999) argumenta que deve ser analisado cada um dos principais sistemas de produção - explicar a sua origem e a sua racionalidade -, o que requer um estudo aprofundado das práticas agrícolas e econômicas de cada grupo de agricultores. Segundo o autor, isso permitiria identificar e hierarquizar os problemas técnicos, ambientais e econômicos que cada grupo de produtores enfrenta, possibilitando também aprofundar o conhecimento sobre o sistema agrário e sobre cada grupo em particular. Assim, no âmbito de uma unidade produtiva, "o sistema de produção agrícola pode ser definido como a combinação (no tempo e no espaço) dos recursos disponíveis para a obtenção das produções vegetais e animais" (DUFUMIER, 2010, p. 85).

Os sistemas de produção agrícola, como assinala Dufumier (2010), são formados pela combinação de subsistemas produtivos, tais como: os sistemas de cultivo, definidos com base nas parcelas ou grupos de parcelas trabalhados de maneira homogênea, seguindo os mesmos itinerários técnicos e sucessões de culturas; os sistemas de criação, definidos com base nos rebanhos ou parte deles e; os sistemas de transformação dos produtos agrícolas. Devido a essa combinação de fatores, deve-se considerar a complexidade interna de cada um dos principais tipos de sistemas de produção agrícola, evitando redução quanto ao seu funcionamento (DUFUMIER, 2010).

É, pois, a partir desse campo de possibilidades proporcionado pelo Diagnóstico do Sistema Agrário de uma região, que objetiva-se situar, no âmbito dos resultados e discussões, a evolução e as principais características dos sistemas de produção da zona homogênea da comunidade de Capela do Caravágio.

\section{METODOLOGIA}

Para realização deste trabalho, foi utilizado o Método Análise e Diagnóstico dos Sistemas Agrários (GARCIA FILHO, 1999), tendo como referência empírica o Município de Vacaria - RS. Geralmente, para 
caracterizar o sistema agrário de um país, região, município ou localidade rural, faz-se uso de uma metodologia pautada no enfoque sistêmico. Opção que se justifica pelo fato dessa metodologia apresentar a possibilidade de explicar os mecanismos internos que orientam e condicionam o contexto agrário da realidade pesquisada (NEUMANN; FIALHO, 2009).

Como descrevem ainda Neumann e Fialho (2009), para observar e analisar a propriedade rural, deve-se considerar o seu conjunto como um todo, ou seja, as inter-relações existentes entre seus elementos, para depois compreendê-la em suas partes, partindo do geral (a região em que estão localizadas as propriedades) para o particular (a localidade rural ou a propriedade agrícola familiar). Dessa forma, como sugerem os autores, seria possível uma análise mais ampla e detalhada das relações da unidade produtiva com o meio que a envolve, possibilitando uma maior segurança para compreender os fenômenos sociais e econômicos de uma determinada região.

Inicialmente, procurou-se fazer uma caracterização agroecossistêmica e socioeconômica através de fontes secundárias, como, por exemplo, o site do Instituto Brasileiro de Geografia e Estatística (IBGE), o Plano Ambiental do Município de Vacaria (2006) e o Plano Estratégico para o Desenvolvimento da Região dos Campos de Cima da Serra (2010). Em um segundo momento, buscou-se realizar uma análise da trajetória histórica da região, para posterior coleta de dados de campo.

A pesquisa de campo ocorreu no período de 23 a 27 de outubro de 2013, no intuito de caracterizar o sistema agrário da região e suas microrregiões. Inicialmente, foi realizado um zoneamento da região proposta, por meio de mapas temáticos e entrevistas com informantes qualificados, dentre eles, os representantes da Empresa de Assistência Técnica e Extensão Rural (Emater-RS), da Secretaria Municipal da Agricultura e do Sindicato dos Trabalhadores Rurais atuante na região. $\mathrm{Na}$ ocasião, esses informantes apresentaram um zoneamento do Município de Vacaria e indicaram os agricultores que poderiam fazer parte das entrevistas históricas. Esse zoneamento constituiu-se como uma referência para a caracterização das microrregiões.

A partir do relato dos informantes qualificados, optou-se em trabalhar com os agricultores familiares da zona homogênea da Capela 
do Caravágio, pois, além de ser uma região pouco estudada, apresenta as seguintes particularidades: a pecuária familiar como principal atividade produtiva; o predomínio de aposentados nas propriedades; a redução da população rural; uma expressiva presença masculina; falta de infraestrutura; e dificuldade no acesso às políticas públicas.

As entrevistas históricas foram realizadas com os agricultores familiares da comunidade da Capela do Caravágio, tomando como base uma enquete para diagnóstico de UPAs. Ainda foi feita uma leitura de paisagem, com os objetivos de verificar se a região era homogênea, identificar os tipos de agricultura e os condicionantes ecológicos das atividades agrícolas, entre outros fatores.

$\mathrm{Na}$ comunidade, existem 41 UPAs, das quais seis foram indicadas pelos informantes qualificados como sendo representativas para compreender a evolução, as características e as modificações ocorridas nas UPAs da microrregião. Dessas seis UPAs, três foram elegidas para a realização da análise econômica. Essas possuem as seguintes características: UPA 1 - Apresenta um sistema de produção de cria em gado de corte que está se reconvertendo para um sistema de ciclo completo, o que poderia indicar, com efeito, que os sistemas de cria não estão sendo viáveis na microrregião; UPA 2 - Possui um sistema de produção de ciclo completo em gado de cria, o que é característico da microrregião, estando presente em $60 \%$ das UPAs, fato que explica a importância da realização da análise econômica dessa unidade, tomando-a como caso modal; UPA 3 - Trata-se de um caso bem sucedido de cria e recria de gado de corte. Foi escolhida para analisar, por meio de uma comparação, a viabilidade das outras UPAs da zona homogênea em se reconverterem para esse sistema de produção.

Uma vez formulado o objetivo e as questões de pesquisa e explanado sobre os procedimentos metodológicos utilizados, adota-se, neste trabalho, as perspectivas de tipologias ou categorias de agricultores apresentadas pelos autores Garcia Filho (1999), Souza et al. (1992), Lima et al. (1995) e Carneiro (1999), situadas anteriormente. Para esses autores, quando se fala em unidade familiar, unidade familiar camponesa ou família camponesa, está se fazendo referência a um tipo de unidade de produção agrícola cuja lógica está centrada quase que exclusivamente no trabalho familiar e na diversidade de estratégias individuais e familiares que deriva dos níveis de capitalização 
disponíveis e das fracas condições de produção, a fim de manter a sua exploração agrícola e, logo, garantir a sua reprodução social. Dito isso, as unidades de produção aqui estudadas, pertencentes a agricultores familiares que trabalham com sistemas de produção de pecuária de corte, enquadram-se nessa perspectiva teórica, como será visto mais adiante.

\section{CARACTERIZAÇÃO DO MUNICÍPIO DE VACARIA}

O Município de Vacaria está inserido na região dos Campos de Cima da Serra, localizado no extremo Nordeste do Estado do Rio Grande do Sul, como demonstra a Figura 1, possuindo uma área de 2.125,00 $\mathrm{km}^{2}$ e uma população de aproximadamente 61.000 habitantes (IBGE, 2010). Vacaria, atualmente, é composta pelos seguintes distritos: Vacaria (sede), Bela Vista, Capão da Herança, Fazenda da Estrela, Refugiado e Coxilha Grande (PLANO..., 2010). 
Figura 1. Mapa de localização do Município de Vacaria/RS

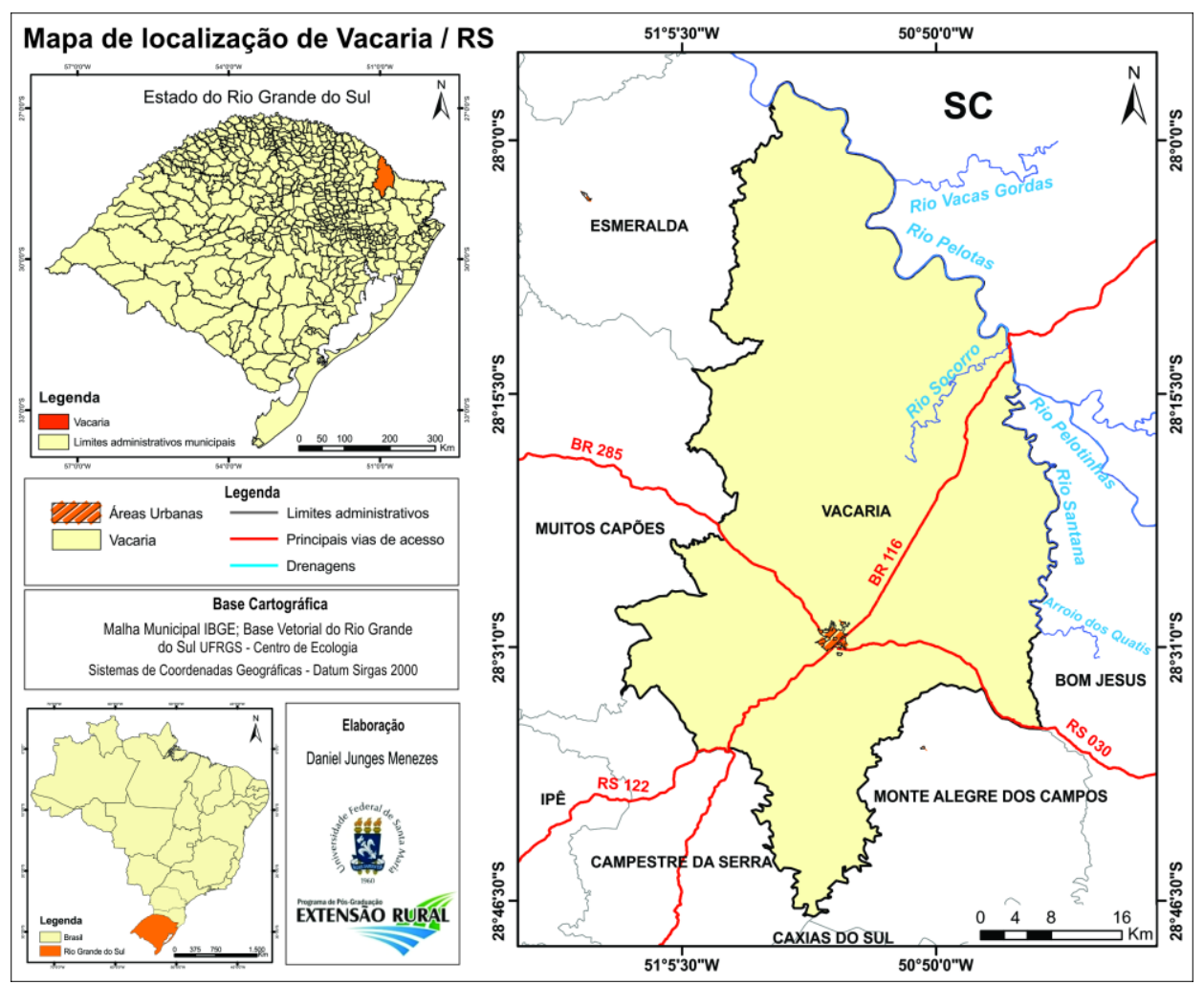

Fonte: Elaborado por Menezes (2013).

Vacaria posiciona-se como cidade polo da região, possuindo mais de $60 \%$ dos habitantes do território. Por isso, encontra-se, no município, a referência em educação, saúde, segurança, financeira, comércio, indústria, de comunicações e serviços (PLANO..., 2010). O setor industrial de Vacaria está representado essencialmente pela agroindústria, ligada à fruticultura e o setor moveleiro. A respeito da saúde, o Hospital do município é responsável pelo atendimento da população local e de comunidades vizinhas. Na educação, Vacaria conta com 11 escolas estaduais e diversas escolas particulares. Conta ainda com a presença de duas Universidades, uma pública e outra privada (PLANO..., 2010).

Em termos de logística, Vacaria ocupa uma situação privilegiada dentro do estado, pois é ligada pela BR 116, conforme destacado na Figura 1, que corta o Brasil de Norte a Sul, ligando o município aos principais centros do país. No sentido leste-oeste, é cortada pela BR 285 , que é a estrada que serve de escoadouro da maior zona produtora do Rio Grande do Sul. Essa estrada liga Vacaria com a fronteira da Argentina no Município de São Borja. Pela situação geográfica que 
ocupa, Vacaria é conhecida como "A Porteira do Rio Grande" (PLANO..., 2006).

Destacam-se, ainda, no Município de Vacaria, as infraestruturas logísticas disponíveis, como aeroporto de cargas, rede ferroviária federal e duas rodovias federais de grande fluxo. O município possui ainda uma grande frota de caminhões. Entretanto, o sistema logístico da região possui uma grande desvantagem competitiva, por conta de estar envolto a três praças de pedágios, o que eleva os custos rodoviários do transporte na região (PLANO..., 2010).

Considera-se que a agricultura é a principal atividade econômica da região, sendo um setor desenvolvido tecnologicamente, principalmente, no que se refere à genética, produção e armazenagem dos produtos agrícolas. Desse modo, a economia da região está mais desenvolvida nesse setor, embora esteja em grande parte condicionado ao preço das commodities a nível internacional, limitando, assim, as margens de operações. No que se refere à organização fundiária, as pequenas propriedades (até 50 hectares) representam $60 \%$ dos imóveis do município, ocupando somente 13\% da área (PLANO..., 2010).

Sendo a agricultura a base da economia da região, o plantio de grãos e a fruticultura despontam como as principais atividades, nas quais se verifica um sistema de produção moderno, com tecnologia aplicada, o que faz com que a região possua um dos melhores índices de produtividade destes setores no Brasil (PLANO..., 2010).

No que diz respeito à fruticultura, especialmente o cultivo de maçã, nota-se que os pequenos e médios produtores encontram-se limitados mercadologicamente, comercializando a produção das frutas para os grandes produtores da região, não participando, com isso, do mercado global. A produção de maçã é responsável por um dos mais complexos fenômenos que ocorre na região, o fluxo imigratório. Todos os anos, a região recebe um número impactante de pessoas que vêm em busca de trabalho, por meio da colheita da fruta. Em Vacaria, esse impacto chega a quase $25 \%$ do número de habitantes do município, aumentando significativamente os seus custos financeiros (PLANO..., 2010).

A respeito da produção animal, a pecuária em Vacaria tem sido a principal atividade do município até algumas décadas. Desenvolvida de forma extensiva, a criação de bovinos não representava somente a base 
econômica do município, mas também passou a fazer parte do ideário cultural da população local. Algumas práticas desenvolvidas pela Emater e pela Secretaria Municipal de Agricultura objetivaram a introdução de melhores técnicas de manejo tanto para a pecuária de corte como de leite, tais como: melhoramento de campo nativo, pastoreio rotativo e melhoramento genético do rebanho (PLANO..., 2010).

A silvicultura também merece destaque no Município de Vacaria, pois existem em torno de 5.000 ha de área destinada à atividade. Dessa área, estima-se que $95 \%$ seja destinada ao cultivo de Pinus elliotti, $4 \%$ ao cultivo de Eucalyptus $s p$. e $1 \%$ ao cultivo de outras espécies (PLANO..., 2010).

Vacaria apresenta condições naturais específicas. Seu relevo característico é montanhoso, com formação de coxilhas. A região apresenta clima subtropical. A média anual máxima de temperatura é de $16^{\circ} \mathrm{C}$, tendo parte do município uma temperatura média anual de $14^{\circ} \mathrm{C}$, fenômeno que possibilitou a introdução da cultura da maçã (PLANO...,2006).

Os solos de Vacaria são do tipo: Cambissolos; Latossolos; Solos Litólicos; Chernossolo. Como vegetação, os tipos fitogeográficos originais que se desenvolvem no Município de Vacaria são a Floresta Estacional Decidual, a Floresta Ombrófila Mista (mata de araucárias) e Savanas, e a altura média é próxima aos 1000 metros (PLANO..., 2006).

As características geomorfológicas do município, ilustradas na Figura 2, também são bastante heterogêneas, com áreas planas na parte central do município, e com áreas de relevo ondulado, especialmente ao norte, junto à encosta do Rio Pelotas e ao sul, junto aos afluentes do Rio das Antas. Nas áreas mais aplainadas, predomina a formação conhecida como coxilhas, com pequeno aprofundamento dos vales fluviais. Nas áreas de maior declividade, verifica-se a presença de relevo muito acidentado, com morros fortemente ondulados, solos rasos e pedregosos, do tipo litólico e cambissolo (PLANO AMBIENTAL MUNICIPAL, 2006).

Figura 2. Mapa geomorfológico de Vacaria/RS 


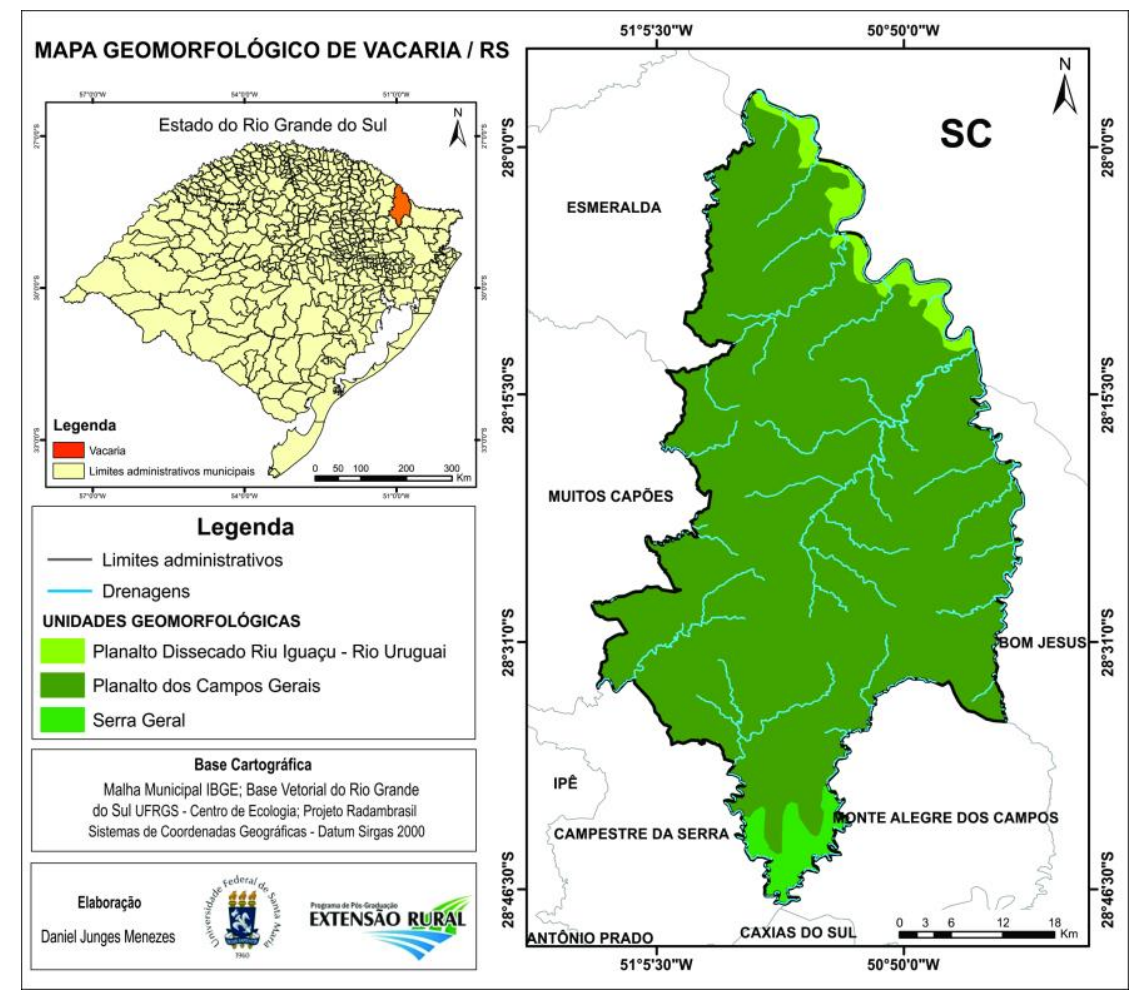

Fonte: Elaborado por Menezes (2013).

A Figura 3 a seguir focaliza a hidrografia da região, evidenciando que um dos principais rios que fazem parte do território de Vacaria é o rio Pelotas, que faz a divisa natural entre os estados do Rio Grande do Sul e Santa Catarina. Nasce no Parque Nacional de São Joaquim na Serra Geral, no Município de Bom Jardim da Serra, próximo às nascentes do rio Laranjeiras e do rio Lava Tudo, a mais de mil metros de altitude, correndo para sul-sudoeste até fazer parte da divisa dos municípios de Bom Jardim da Serra e São Joaquim. Ao chegar à divisa do Estado de Santa Catarina com o Rio Grande do Sul, passa a correr para o oeste. É um afluente do rio Uruguai, que vai à Bacia Platina e, daí, por sequência, ao Oceano Atlântico. Além desse, sobressai-se o Rio das Antas, que faz parte da Bacia Taquari-Antas (PLANO AMBIENTAL MUNICIPAL, 2006). 
Figura 3. Mapa hidrográfico de Vacaria/RS

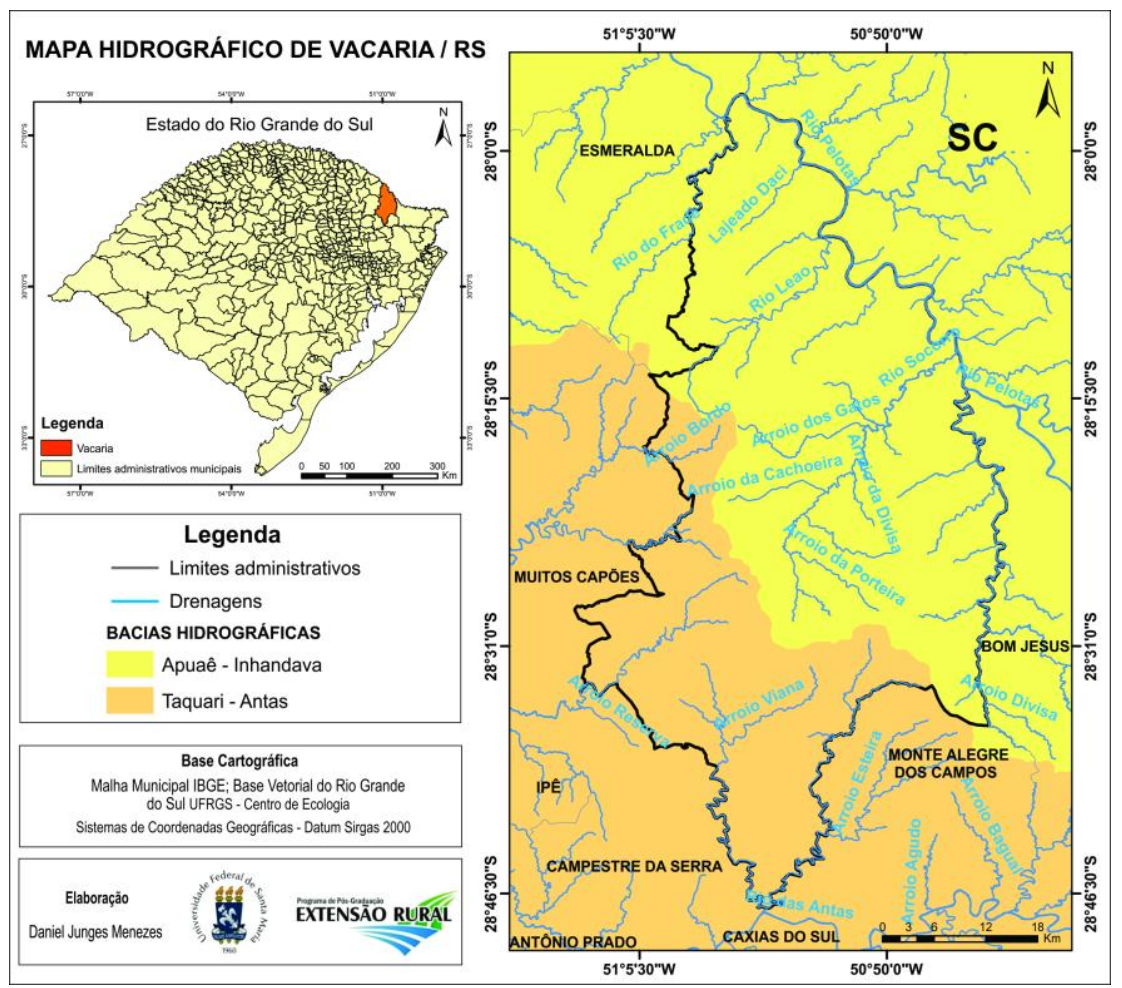

Fonte: Elaborado por Menezes (2013).

\section{RESULTADOS E DISCUSSÃO}

O $6^{\circ}$ Distrito de Vacaria, Coxilha Grande, possui uma área total de $397,91 \mathrm{~km}^{2}$ e duas zonas geográficas com distintas características. A partir dos relatos dos informantes qualificados e dos agricultores entrevistados nesta pesquisa, constata-se que os recursos naturais, a hidrografia e as condições climáticas não são os fatores determinantes para a existência dos diferentes tipos de produção no município. Ao mesmo tempo, existe diferença no relevo: a Zona Oeste é plana, enquanto que a Zona Oeste apresenta-se de forma ondulada, pedregosa e montanhosa.

A região tem um histórico de pecuária que foi sendo substituído, nos últimos anos, pela produção de grãos e pela fruticultura. Porém, a pecuária permanece na região, sobretudo em áreas onde os produtores não têm condições de se inserir na dinâmica produtiva dos grãos e das frutas. Além disso, nos últimos anos, foi constatado um forte processo de êxodo rural, mas que, atualmente, parece estar estabilizado, segundo os produtores. 
A Figura 4 a seguir categoriza o uso do solo na microrregião central de Vacaria e em quatro de seus Distritos, incluindo o de Coxilha Grande. Na zona Oeste, onde predominam as produções de grãos (soja, milho), de maçã e a pecuária, as propriedades variam de 200 ha até 500 ha, e os produtores se encontram em níveis mais avançados de capitalização. A zona Leste, por outro lado, é uma região onde a pecuária apresenta-se como alternativa para muitos dos agricultores marginalizados pela dinâmica produtiva dos grãos e da maçã, devido à falta de infraestrutura e capital para investimentos. Seus estabelecimentos são menores e variam entre 60 ha e 70 ha, destacando-se as atividades da pecuária, e as produções de grãos e uva e o reflorestamento (em menores escalas).

Figura 4. Mapa de uso do solo da microrregião central do Município de Vacaria/RS, incluindo o $1^{\circ}, 2^{\circ}, 3^{\circ}$ e $6^{\circ}$ Distritos

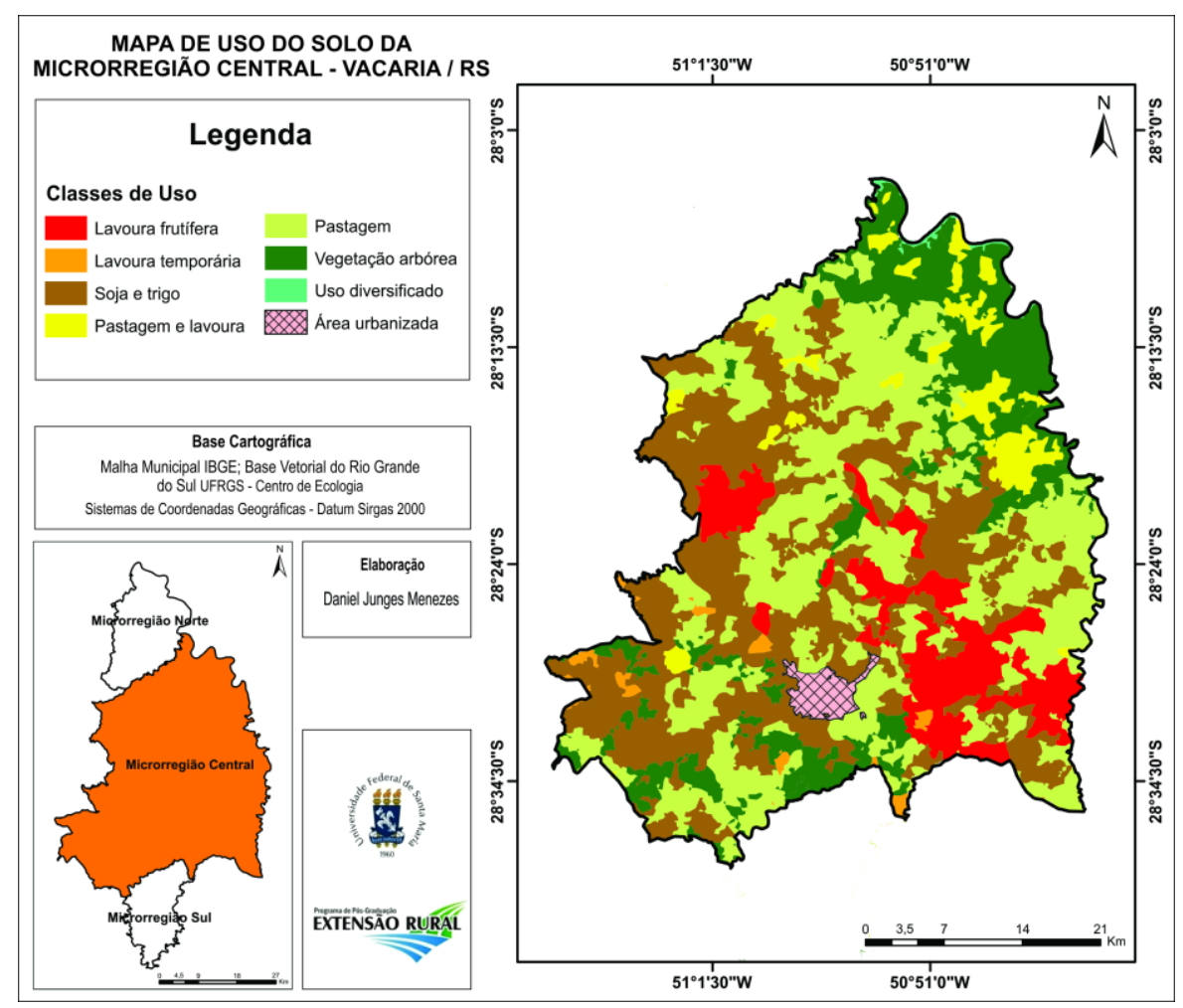

Fonte: Elaborado por Menezes (2013).

Por meio das entrevistas históricas, tornou-se possível identificar a evolução dos sistemas de produção, cultivo e criação e a relação entre as mudanças socioeconômicas e técnicas, identificando alguns fatores que provocaram as diferenciações na região. A tradição pecuarista da 
região está intimamente relacionada à presença de um grande frigorífico nas décadas passadas, onde 90 mil animais eram abatidos por ano, além de gerar 900 empregos diretos. Entretanto, o frigorífico inicia um período de crise a partir do ano de 1985, estabelecendo-se, com efeito, um endividamento entre os produtores locais. O seu fechamento ocorreu no ano de 1997, dificultando o escoamento da produção dos pecuaristas locais, especialmente pela falta de um canal de comercialização nas proximidades do município. Isso desencadeou o abandono da atividade por parte de alguns produtores, ou ainda, a busca pela diversificação produtiva daqueles que continuaram com a atividade pecuária em suas propriedades.

Também é importante comentar, que, na década de 1940, surgiram muitas serrarias, atividade que teve seu melhor desempenho nas décadas de 1950 e 1960, até que se acabaram as Araucárias. A partir de 1975, impulsiona-se o crescimento da agricultura, principalmente com a produção de grãos, na qual a soja começa a substituir o trigo e a pecuária. No mesmo período, a fruticultura desponta como uma potencialidade, merecendo destaque a produção de maçã, que visava criar fontes de emprego, pelas características ambientais favoráveis à produção de frutas. O ano de 1988 é marcado pelos projetos para divulgação e financiamento da cultura. Vale ainda dizer que muitos dos empregados (embaladores de fábricas, trabalhadores de indústrias) da maçã tornaram-se empresárioprodutores nos anos seguintes. Considera-se que o conjunto de ações decorrentes desse período marca a produção de maçã como a principal dinâmica econômica do município. Mais importante, inclusive, que a soja, em termos de mão de obra empregada.

Dentro da dinâmica atual, procurou-se levantar, por meio das entrevistas, algumas potencialidades e limitações da produção de maçã, das pequenas frutas, da produção de grãos e da pecuária. Entre as potencialidades da cultura da maçã, destacam-se: o excelente clima para a produção da fruta; a possibilidade de comercialização e exportação; possibilidades de diversificação da produção, inserindo novas frutas nas propriedades; e geração de empregos diretos e indiretos. No campo das limitações, constata-se: falta de mão de obra qualificada; aumento da população do município durante a safra, o que compromete os serviços de saúde, segurança, transporte, etc.; danos 
ambientais provocados pelo sistema produtivo, já que a cultura da maçã demanda a introdução de espécies em um sistema, com alto aporte de insumos externos (adubos, corretivos e agrotóxicos), grande alteração das condições naturais (preparo do terreno) e trânsito constante de pessoas ou máquinas durante todo o ano (GEBLER, 2002); problemas na comercialização do município (venda exclusiva para embaladores, falta de canais alternativos, falta de cooperativas); grande concentração da produção, o que dificulta uma melhor distribuição da renda; elevados custos de produção e baixo lucro para o produtor; falta de organização entre pequenos e médios produtores na busca de alternativas para a comercialização e industrialização; e dificuldades no acesso ao Programa Nacional de Fortalecimento da Agricultura Familiar (Pronaf), seja pela falta de informações sobre essa política pública, seja pelos entraves burocráticos para o enquadramento nas linhas de crédito do programa.

As vantagens identificadas na produção de grãos, segundo relatos, foram: uma melhor remuneração para os trabalhadores assalariados, quando comparada a outras produções; e uma maior possibilidade de se conseguir algum tipo de financiamento. Entre os problemas, destacou-se, na fala dos entrevistados: um insuficiente sistema de armazenagem, que compromete o desenvolvimento do setor e uma produção comercializada in natura sem valor agregado.

No que diz respeito às pequenas frutas, os produtores relatam que essa produção vem se apresentando como uma alternativa à produção das frutas tradicionais. Entretanto, a atividade necessita de organização, infraestrutura, ações coletivas e uma dinâmica de comercialização conjunta, pois, individualmente, os custos ficam muito elevados. Sobre a pecuária, conforme já citado neste trabalho, é uma atividade desenvolvida como alternativa para alguns agricultores excluídos da dinâmica produtiva dos grãos e das frutas.

Particularizando a zona homogênea da Capela do Caravágio, os dados revelam que, nessa comunidade, geralmente, não há trabalhadores assalariados. A produção pecuária é destinada para o frigorífico municipal, e a complementação de renda dos agricultores é proveniente da produção de hortaliças e outros produtos comercializados em feiras locais ou venda direta. De acordo com os produtores e a realidade observada, a microrregião apresenta $\mathrm{o}$ 
predomínio de aposentados nos estabelecimentos; a redução da população nos últimos anos e uma expressiva presença masculina no meio rural; e a falta de infraestrutura em serviços de transporte, saúde e educação.

A zona homogênea possui 41 estabelecimentos, predominando a pecuária familiar (sistemas de cria e de ciclo completo) associada a outras produções, principalmente hortaliças. Os primeiros habitantes da localidade eram imigrantes de italianos dedicados à cultura do trigo. A pecuária ganhou espaço pela dificuldade da concorrência com as grandes lavouras. Atualmente, os produtores encontram dificuldades na comercialização e escoamento da produção. Problemas como a falta de acesso às políticas públicas e os endividamentos também aparecem na fala dos produtores entrevistados. A seguir, será apresentada uma caracterização de três UPAs da Capela do Caravágio e a análise econômica de cada uma delas.

UPA 1: Pecuária Familiar em transição para ciclo completo, com renda proveniente de terras arrendadas

A Unidade de Produção 1 possui uma área total de 65 ha. Destes, 20 ha são arrendados para a produção de grãos, 5 ha são de mata nativa e 40 ha representa a Superfície de Área Útil (SAU) destinados aos sistemas de produção ( 32 ha de lavoura e 8 ha de campo nativo).

O sistema dispõe de um equivalente a 1,9 Unidade de Trabalho Homem (UTH), composto por um casal de produtores (o homem de 63 anos e a mulher de 56 anos). O casal é de aposentados e ambos trabalham de forma exclusiva na UPA, sendo que, em determinado período do ano, é contratado um trabalhador por dois meses.

A respeito do sistema de produção, a propriedade tem como principal fonte de renda a pecuária de corte com o sistema de cria, que está se convertendo para ciclo completo. Além disso, são realizadas atividades complementares para melhorar a renda e também para o autoconsumo, acentuando-se a produção de leite, queijo, mel, criação de aves e suínos. Como fontes externas para a alimentação dos animais são comprados grãos de milho, que são utilizados para os suínos, bovinos e aves. Para a alimentação dos suínos, também é aproveitado o soro de leite. Os objetivos principais dos produtores, em médio prazo, 
são a consolidação do sistema de ciclo completo e o aumento da área de pastagem para a criação de 15 terneiros por ano.

Para manutenção da propriedade, o produtor utiliza recursos do Pronaf para custear as vacinas obrigatórias e o controle sanitário do seu rebanho. O produtor também possui outro financiamento particular no valor de $R \$ 9.078,00$, que será pago em oito parcelas anuais. Esse financiamento foi feito para a compra de máquinas e implementos. A respeito dos serviços de assistência técnica, o produtor recebe visitas esporádicas da Emater. Na Tabela 1 é apresentado o resumo das análises econômicas realizadas na UPA 1, e o Gráfico 1 representa o VAL e RA necessários para atingir o nível de reprodução simples (NRS) da mesma. 
Tabela 1. Indicadores de Resultado Anual da Unidade de Produção Agrícola 1

\begin{tabular}{lr}
\hline Indicador & Valor (em R\$) \\
\hline Produto Bruto (PB) & 17.825 \\
Consumo Intermediário (Cl) & 2.297 \\
PB/Cl & 7,76 \\
Valor Agregado Bruto & 15.527 \\
Total Depreciação & 2.106 \\
Valor Agregado Líquido & 13.421 \\
Distribuição do Valor Agregado & 3.117 \\
Renda agrícola anual & 10.304 \\
Renda agrícola mensal/UTH & 452,1 \\
Renda não agrícola & 35.000 \\
Nível de Reprodução Simples & 19.186 \\
NRS mensal/UTH & 841,5 \\
\hline
\end{tabular}

Fonte: Elaborada pelos autores.

1) Análise do NRS: com uma área total de 40 ha de SAU, a unidade de produção obtém uma renda agrícola de $R \$ 10.304$, valor que supera os custos de produção da propriedade, entretanto, não consegue atingir o NRS de R\$19.186 anuais. Nesse sentido, a atividade agrícola não Ihe permite garantir a reprodução das condições de produção e o trabalho familiar ao longo prazo. Porém, o nível mínimo de reprodução simples é garantido por meio das rendas obtidas fora do sistema de produção da UPA (aposentadoria dos agricultores). Dessa forma, em uma situação de longo prazo, caso a UPA 1 mantenha o mesmo sistema de produção, a tendência é que ocorra uma descapitalização gradativa, tendo como consequência o abandono desse modo de produção, ou substituição por uma produção que atinja o nível mínimo de NRS. Some-se a isso o problema da sucessão familiar identificada nessa UPA, tendo em vista que os filhos do casal não residem na propriedade, justamente pela falta de condições que desestimularam a sua permanência no campo. Nesse caso em questão, pela dificuldade para o acesso aos estudos e insatisfação com a renda advinda da agricultura, o que tende a um envelhecimento do meio rural.

2) Com relação à análise da trajetória da evolução da unidade de produção, é possível afirmar que a UPA encontra-se em fase de reestruturação, pois o sistema de pecuária de corte de cria está passando por uma conversão para o sistema de ciclo completo. $\mathrm{O}$ 
produtor também pretende aumentar a sua área de pastagem para conseguir uma criação de 15 terneiros por ano. A UPA apresenta condições de se manter pelos próximos 10 a 15 anos, haja vista que tem a capacidade de cumprir suas metas por meio das estratégias estabelecidas pelos produtores. É possível afirmar, nesse caso, que o tempo exato de funcionamento da UPA depende exclusivamente do tempo que o casal permanecerá trabalhando, pois não há sucessores para a continuidade das atividades na propriedade.

3) Análise do desempenho do sistema: a partir dos dados presentes no Gráfico 1, constata-se que a UPA necessitaria de mais 15 ha de SAU para obter uma renda agrícola satisfatória, na qual os produtores não precisariam depender de outras fontes de renda. $\mathrm{O}$ fator limitante para isso é a falta de mão de obra na propriedade, pois, se houvessem mais trabalhadores, a produção poderia ser mais diversificada, havendo um incremento na renda. A idade dos produtores é um fator condicionante para a não implementação de atividades complementares.

\section{Gráfico 1. Relação do Valor Agregado Líquido e Nível de Reprodução Simples para a Unidade de Produção Agrícola 1}

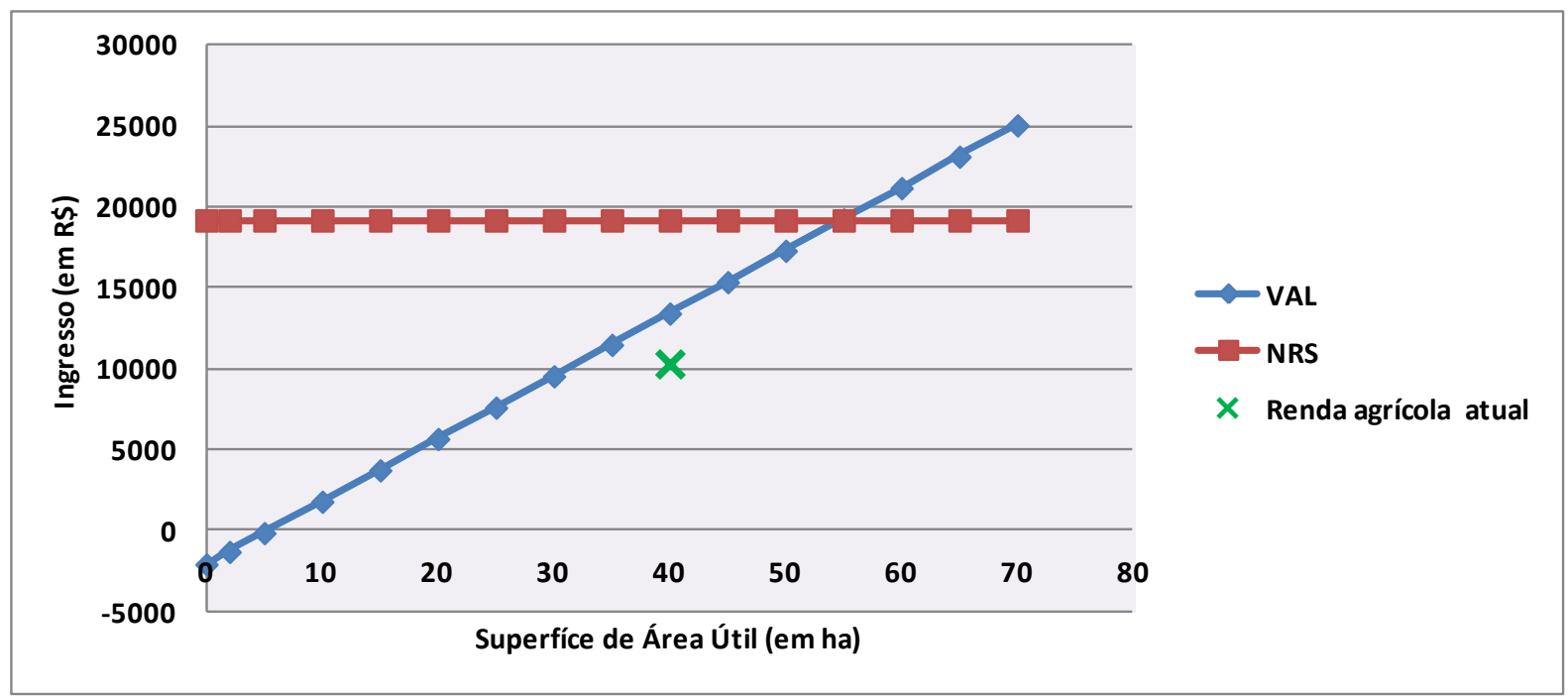

Fonte: Elaborado pelos autores.

UPA 2: Pecuária Familiar de ciclo completo (em terras próprias e arrendadas)

A segunda UPA analisada tem como fonte de renda predominante o sistema de produção de pecuária de corte em ciclo completo. Além 
dessa atividade principal, ocorre também a criação de suínos e a produção de mel e queijo como atividades complementares. $O$ trabalho é realizado por um casal de aposentados de 73 (homem) e 66 (mulher) anos, com dedicação exclusiva à propriedade.

As tarefas são divididas, a mulher trabalha nas atividades de agroindustrialização dos produtos secundários e de autoabastecimento da UPA (queijo e mel), e o homem dedica-se ao trabalho com os animais e a comercialização dos produtos. Nos períodos de maior necessidade de mão de obra, recorrem à ajuda familiar de dois filhos que não residem na propriedade. A pecuária é realizada em campo nativo, com suplementação de milho comprado, e, apenas no inverno, é arrendada uma lavoura para a manutenção e engorda do gado, utilizando uma SAU de 91 ha. 


\section{Tabela 2. Indicadores de Resultado Anual da Unidade de Produção} Agrícola 2

\begin{tabular}{lr}
\hline Indicador & Valor (em R\$) \\
\hline Produto Bruto & 34.932 \\
Consumo Intermediário & 6.256 \\
PB/Cl & 5,58 \\
Valor Agregado Bruto & 28.676 \\
Total Depreciação & 1.350 \\
Valor Agregado Líquido & 27.326 \\
Distribuição do Valor Agregado & 23.803 \\
Renda agrícola anual & 3.523 \\
Renda agrícola mensal/UTH & 196 \\
Renda não agrícola & 18.000 \\
Nível de Reprodução Simples & 15.015 \\
NRS mensal/UTH & 834,2 \\
\hline
\end{tabular}

Fonte: Elaborada pelos autores.

1) Análise do nível de reprodução simples: a partir dos dados coletados e analisados, percebe-se que a UPA não consegue obter uma renda agrícola que permita atingir o nível de reprodução simples da mão de obra. O desempenho econômico proporciona uma renda anual de $R \$ 3.523$, o que fica muito abaixo do NRS, calculado em $R \$ 15.015$ anuais. Isso porque se verifica que essa UPA tem uma Distribuição do Valor Agregado elevada, fato que está associado, principalmente, ao gasto com arrendamentos, que atinge o valor de $R \$ 23.000$ anuais. Tal fato é determinante para condicionar a baixa renda agrícola identificada nessa UPA. As práticas agropecuárias se encontram abaixo do nível esperado, porém, com a renda não agrícola, o produtor tem condições de se manter e até mesmo de se capitalizar, quando comparado com o valor do NRS.

2) Análise da trajetória da evolução da UPA: a unidade de produção mantém o mesmo sistema há vários anos, encontrando-se em uma fase de estabilidade, embora os indicadores de produção levem o sistema a uma crise e forte dependência das rendas não agrícolas. A composição familiar indica que o sistema tende a regredir, devido à avançada idade dos produtores e pela falta de sucessores na unidade de produção. Os filhos, que contribuem com mão de obra ocasionalmente, possuem outras atividades e não residem no estabelecimento. 
3) Análise do desempenho do sistema: considerando que, com os 91 ha de SAL, a UPA não consegue uma renda agrícola que permita atingir o patamar de reprodução simples, necessitando recorrer às rendas não agrícolas para permanecer com as atividades produtivas, torna-se necessário compreender as causas determinantes dos resultados.

O sistema analisado atingiria o patamar de reprodução simples com apenas $52 \mathrm{ha}$, isso se o produtor contasse exclusivamente com terras próprias, porém, nesse caso especifico, existe uma forte dependência de terras arrendadas. Conforme expõe o Gráfico 2, é a partir de 128 ha que o NRS é atingido, ou seja, somente a partir desse momento o produtor teria condições de se capitalizar. 


\section{Gráfico 2. Relação do Valor Agregado Líquido e Nível de Reprodução} Simples para a Unidade de Produção Agrícola 2

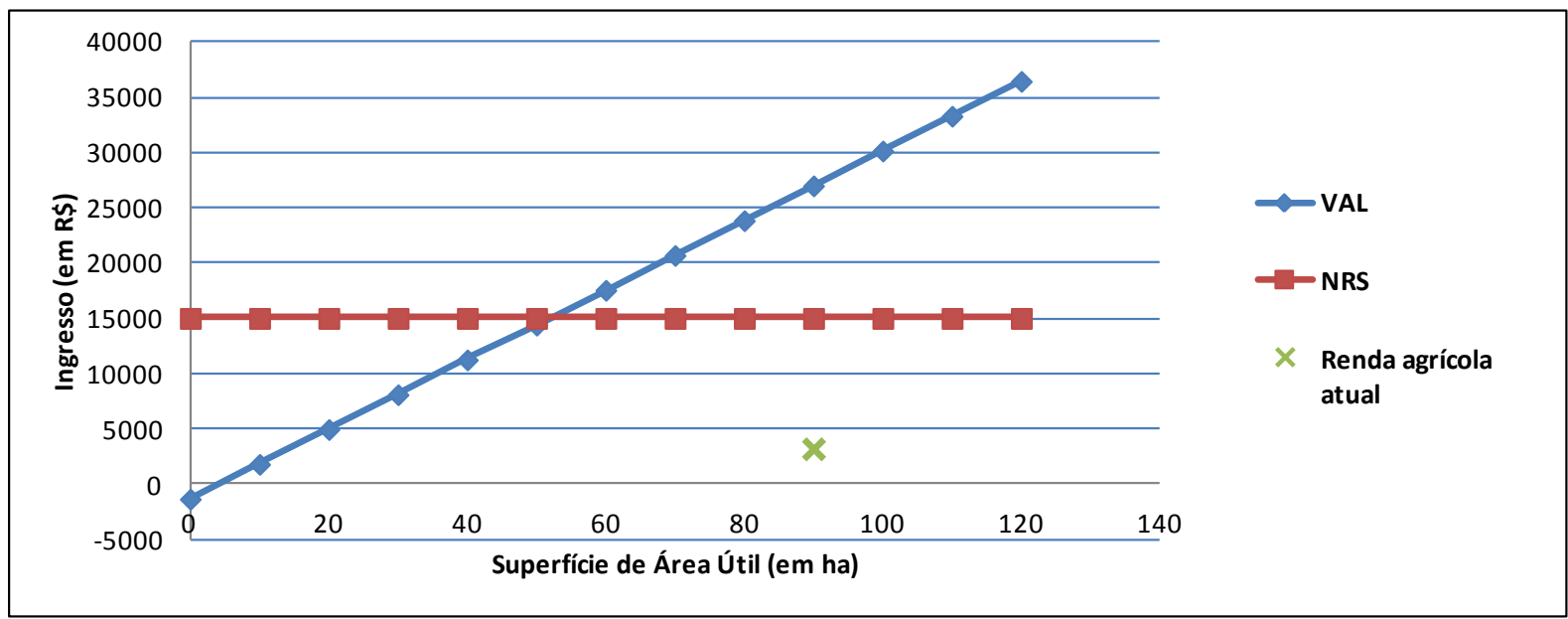

Fonte: Elaborado pelos autores.

Pela análise dos dados da Tabela 2, percebe-se que a UPA apresenta um elevado custo de arrendamento (o que determina o elevado DVA) em comparação com o VAL, o que pode ser explicado pela comercialização da carne bovina, considerada o produto principal do sistema.

Após uma simulação mais detalhada para a compreensão dos resultados obtidos, verifica-se que, o efeito dos preços de venda da produção incide fortemente no resultado econômico, no VAL e na renda agrícola, pois o sistema é muito sensível às variações de preços, o que é demonstrado com a comparação entre o cenário mais negativo com o cenário mais positivo.

No primeiro caso, com a venda de todos os animais a um preço de $\mathrm{R} \$ 2,50 / \mathrm{kg}$ (preço mínimo obtido durante o ano analisado), o produtor teria uma renda agrícola negativa de $R \$-385,00$ anuais. Já no melhor dos cenários, vendendo toda a sua produção a um preço máximo de $\mathrm{R} \$ 3,30 / \mathrm{kg}$, sua renda agrícola aumentaria para $\mathrm{R} \$ 7.431,00$ anuais. A família é notavelmente sensível às flutuações do mercado da pecuária de corte, sendo necessária uma melhor compreensão dos aspectos de comercialização, como o conhecimento das variações de preços, canais de comercialização e controle mais adequado do sistema de produção.

UPA 3: Pecuária Familiar de cria, predominando o uso de terras arrendadas 
A terceira unidade de produção corresponde a um sistema de cria de gado de corte, com recria até os 15 meses. O sistema utiliza 68 ha de área da propriedade e 700 ha arrendados, com uma SAU de 751 ha. A mão de obra é familiar e exclusiva de um casal (homem de 62 anos e mulher de 58 anos), e de forma parcial do filho de 23 anos. A unidade ainda conta com mão de obra contratada de forma permanente de um trabalhador assalariado.

A produção é realizada em campo nativo, na área arrendada, pois na área própria são produzidas a silagem de milho e a pastagem, que servem de alimentação para o gado. A estratégia da unidade de produção é aumentar a receita a partir da escala de produção. A possibilidade do arrendamento de 700 ha permite obter um PB de $\mathrm{R} \$ 188.100,00$, com um total de despesas (Consumo Intermediário e Distribuição do Valor Agregado) de $\mathrm{R} \$ 101.368,00$. A alimentação comprada, o arrendamento e a mão de obra contratada representam $82 \%$ desse total.

\section{Tabela 3. Indicadores de Resultado Anual da Unidade de Produção}

\section{Agrícola 3}

\begin{tabular}{lr}
\hline Indicador & Valor (em R\$) \\
\hline Produto Bruto & 188.100 \\
Consumo Intermediário & 74.482 \\
PB/CI & 2,53 \\
Valor Agregado Bruto & 113.618 \\
Total Depreciação & 6.938 \\
Valor Agregado Líquido & 106.680 \\
Distribuição do Valor Agregado & 26.886 \\
Renda agrícola anual & 79.794 \\
Renda agrícola mensal/UTH & $2.015,2$ \\
Renda não agrícola & 18.000 \\
Nível de Reprodução Simples & 32.533 \\
NRS mensal/UTH & 821,5 \\
\hline
\end{tabular}

Fonte: Elaborada pelos autores.

1) Análise do NRS: este sistema de produção atinge o NRS anual e permite a realização de investimentos na propriedade, capitalizando o proprietário. Esse NRS é atingido apenas com 250 ha, se comparado com o VAL, mas, neste caso, ao dispor de terras arrendadas e mão de obra contratada (como as principais 
distribuições do valor agregado), necessitam de 450 ha para atingir o NRS.

2) Análise da trajetória da evolução da UPA: o sistema encontra-se em fase de estabilidade. Há a previsão de manutenção dos produtores na atividade, o que pode ocorrer tanto pela idade dos mesmos quanto pela existência de sucessão familiar, pois o filho pretende continuar com as atividades agropecuárias da família.

\section{Gráfico 3. Relação do Valor Agregado Líquido e Nível de Reprodução Simples para a Unidade de Produção Agrícola 3}

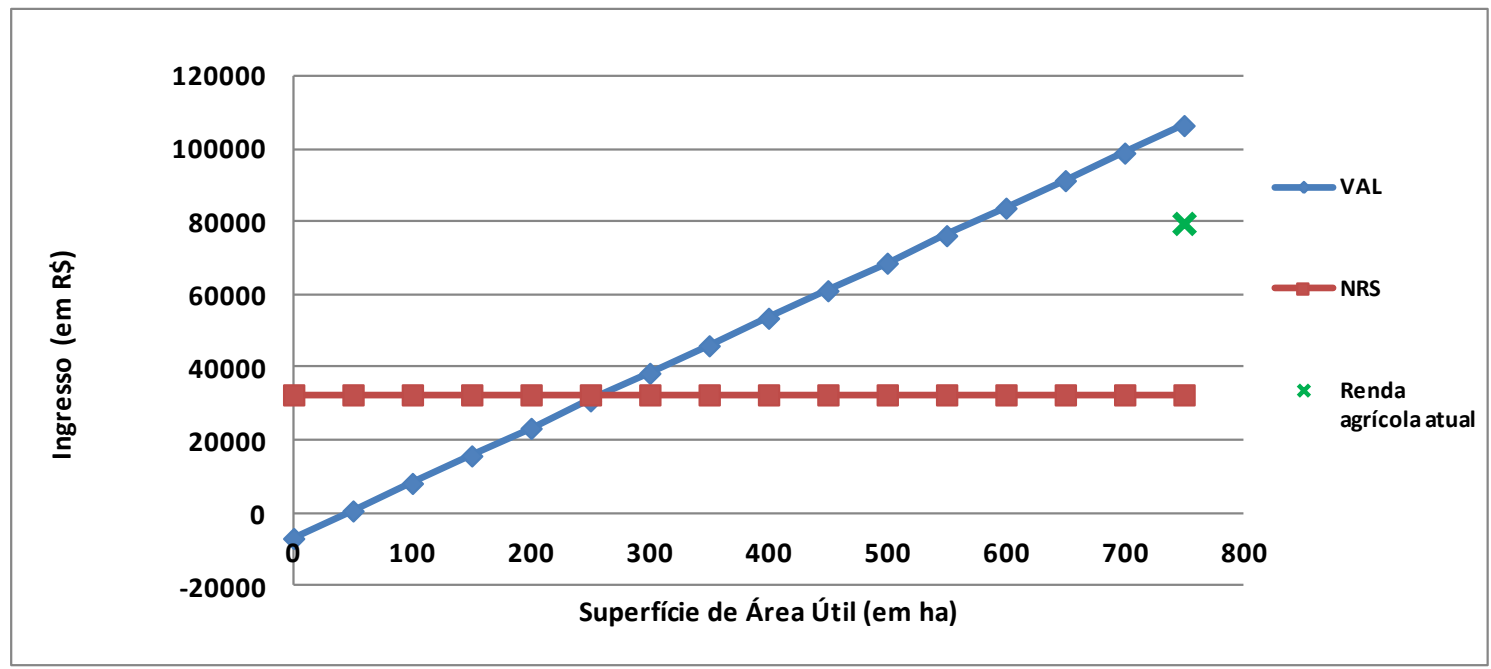

Fonte: Elaborado pelos autores.

1) Análise do desempenho do sistema: embora sejam elevados os custos de produção do sistema, em comparação com a produção, obtém-se uma renda agrícola positiva devido à escala produtiva.

2) Análise da capacidade e das alternativas de reprodução: o sistema permite uma poupança anual de $R \$ 65.261,00$, se comparada à Renda global (agrícola e não agrícola) com o NRS anual. Um fator que pode ser observado nesse sistema, que de fato apresenta bons rendimentos e permite a reprodução econômica da família, é o vínculo e a dependência que o mesmo tem com a superfície arrendada. Considerando a capacidade de investimento anual, deve ser estudada pelos proprietários a possibilidade de compra de terras, prevendo situações futuras de instabilidade em relação ao preço dos produtos, mas principalmente dos arrendamentos.

\subsection{Análise do desempenho dos sistemas}


Alguns apontamentos já foram realizados na análise de cada UPA, entretanto, a forma mais segura de avaliar o desempenho do sistema é realizando uma comparação entre os sistemas semelhantes ou baseados em referenciais teóricos. Portanto, serão retomadas as análises comparativas entre as três UPAs a partir das informações coletadas e esquematizadas na Tabela 4.

\begin{tabular}{|c|c|c|c|}
\hline Indicador & UPA 1 & UPA 2 & UPA 3 \\
\hline Superfície de Área Útil (SAU) & 40 há & 91 ha & 751 há \\
\hline Unidade de Trabalho Homem (UTH) & 1,9 & 1,5 & 3,3 \\
\hline Produto Bruto/ha & $\mathrm{R} \$ 445,6$ & $\mathrm{R} \$ 383,9$ & $\mathrm{R} \$ 250,5$ \\
\hline Consumo Intermediário/ha & $\mathrm{R} \$ 57,4$ & $\mathrm{R} \$ 68,7$ & $\mathrm{R} \$ 99,2$ \\
\hline Valor Agregado Bruto/ha & $\mathrm{R} \$ 388$ & $\mathrm{R} \$ 315$ & $\mathrm{R} \$ 151$ \\
\hline Depreciação/ha & $\mathrm{R} \$ 52,7$ & $\mathrm{R} \$ 14,8$ & $\mathrm{R} \$ 9,2$ \\
\hline Valor Agregado Líquido (VAL)/ha & $\mathrm{R} \$ 336$ & $\mathrm{R} \$ 300$ & $\mathrm{R} \$ 142$ \\
\hline VAL/UTH & $\mathrm{R} \$ 7.064$ & $\mathrm{R} \$ 18.217$ & $\mathrm{R} \$ 32.327$ \\
\hline Renda agrícola anual & $R \$ 10.304$ & $\mathrm{R} \$ 3.523$ & $\mathrm{R} \$ 79.794$ \\
\hline Renda/UTH/Mês & $\mathrm{R} \$ 448$ & $\mathrm{R} \$ 196$ & $\mathrm{R} \$ 2.046$ \\
\hline Renda agrícola/NRS & 0,53 & 0,23 & 2,5 \\
\hline
\end{tabular}

Fonte: Elaborada pelos autores.

Conforme demonstra a tabela anterior, percebe-se que a UPA 3 tem uma elevada renda agrícola, embora tenha pior desempenho técnico e econômico (menor $\mathrm{VAB} / \mathrm{ha}$ e $\mathrm{VAL} / \mathrm{ha}$ ). Isso se deve exclusivamente à extensão de área que a UPA possui. Essa característica permite pequenos investimentos por unidade de superfície que, multiplicado pela área total, ocasiona um aumento na renda agrícola anual, refletindo na diluição dos custos de depreciação.

A UPA 1 tem uma estrutura desproporcional, evidenciado no indicador de depreciação por superfície (Dep/ha) com relação às outras duas UPAs, indicando que o sistema tem instalações ociosas para esse tipo de produção, embora seja um sistema em conversão. A produção por ha (PB/ha) indica que o nível de produção é aceitável, o que também determina um $\mathrm{VAB} /$ ha e $\mathrm{VAL} /$ ha maior do que as demais UPAs. O fato é que a UPA 1 , embora tenha indicadores técnicos melhores que as outras UPAs, caracteriza-se como um sistema extensivo, onde o tamanho da 
área não permite uma renda maior. Essa situação se verifica também na UPA2, onde a relação entre entradas e saídas de capital é ainda mais restrita.

A Renda Agrícola/NRS indica a proporção de salários mínimos por trabalhador que a UPA consegue obter. No presente estudo, verifica-se que tanto a UPA 1 quanto a UPA 2 não conseguem obter a renda de um salário mínimo por trabalhador, sendo que a primeira tem uma renda de 0,53 salários mínimos/trabalhador, enquanto que a UPA 2 tem uma renda ainda mais baixa, com apenas 0,23 salários mínimos/trabalhador. Esse fator está distante de uma viabilidade socioeconômica capaz de assegurar a permanência das famílias no meio rural, pois, para garantir a reprodução social dos agricultores, seria necessária uma renda de, pelo menos, um salário mínimo por pessoa para que não existisse a dependência de outras rendas. Os sistemas vêm conseguindo se manter com a pecuária extensiva, mas a falta de área útil necessária, somada à necessidade de um manejo diferenciado nas áreas de pastagens, por exemplo, compromete a obtenção de uma renda agrícola em um nível desejado, como acontece no caso da UPA 3.

Cabe destacar a importância das rendas não agrícolas para os produtores, sobretudo para as UPAs 1 e 2 , onde esses rendimentos vêm permitindo as duas unidades atingir o nível de reprodução simples e manter seus sistemas de produção. Sem essas rendas, os dois sistemas entrariam em crise e, consequentemente, haveria a saída ou migração dessas atividades desenvolvidas até o momento. A alternativa da UPA 1 foi a conversão para um sistema de ciclo completo, que lhe permitiria um melhor resultado econômico, desde que, conforme análise da UPA2, sejam controlados rigorosamente os canais de comercialização da produção.

\section{CONSIDERAÇÕES FINAIS}

Por meio da elaboração de um diagnóstico dos sistemas de produção da zona homogênea da Comunidade da Capela do Caravágio, foi possível constatar que os sistemas de produção de pecuária de corte, atividade realizada na maioria dos casos por aposentados da localidade, necessitam de uma SAU de pelo menos 60 ha próprios para ter um ingresso mínimo que permita atingir o patamar de reprodução simples, 
caso apresentem indicadores produtivos adequados a essa escala produtiva. Do contrário, por serem sistemas extensivos, os produtores tornam-se dependentes de uma maior superfície e de maior escala de produção e, com isso, do arrendamento de outras terras para desenvolverem suas atividades, ingressando em outro mercado (imobiliário) que pode se apropriar do valor gerado por suas atividades produtivas.

Nos casos analisados, os agricultores familiares dependem das rendas não agrícolas para manter os seus sistemas de produção. Isso explica a dinâmica da pecuária na região, que foi incorporada pelos agricultores familiares que não conseguiam concorrer com a produção de grãos e que, atualmente, é mantida pela aposentadoria dos agricultores e o arrendamento de outras terras. A idade avançada de alguns produtores e a falta de sucessores vêm impossibilitando a reconversão para sistemas de produção mais rentáveis, o que vai condicionar as futuras dinâmicas agrícolas da região.

O histórico da zona homogênea da Comunidade da Capela do Caravágio, assim como as entrevistas realizadas neste trabalho, indicam que os produtores locais foram estimulados a converter seus sistemas de produção para a pecuária de corte, isto porque a falta de recursos econômicos e os insuficientes meios de produção, comprometeram, ao longo dos anos, a concorrência entre os demais sistemas de produção das regiões, seja no próprio distrito ou no município como um todo. Assim, sob distintas condições de utilização dos recursos naturais, enquanto outras regiões especializavam-se na produção de grãos, a Capela do Caravágio adotou a pecuária de corte como principal atividade econômica.

Constata-se, ainda, que algumas das possíveis intervenções a serem realizadas no âmbito do desenvolvimento rural dependem de um forte apoio das instituições locais para que os futuros projetos elaborados para a região possam se desenvolver de forma adequada. Tanto as instituições públicas quanto as privadas são atores-chave nessas transformações. Igualmente, as formulações de medidas de intervenção que possam contribuir para o desenvolvimento rural da região dependem, primeiramente, da articulação entre os diversos agentes locais, norteado por um serviço de extensão rural forte e comprometido em suas ações. 
Entretanto, na atual situação, com os escassos recursos humanos destinados ao município, observa-se que as prioridades das ações de extensão não estão contemplando, em um primeiro momento, os agricultores familiares com sistemas de pecuária de corte. Fatores como as condições naturais, os sistemas de produção, a história da região e a definição de prioridades têm direcionado os serviços de extensão para outros tipos de produtores, em processos produtivos mais organizados. Somente uma mudança nesse quadro, apoiada, principalmente, pela extensão rural, mas também com o apoio de instituições públicas e privadas, poderia proporcionar contribuições para o desenvolvimento rural, pois, sem isso, parece pouco provável que os produtores (submetidos a leis de mercado e sem recursos e incentivos) consigam garantir a sua reprodução social a partir da pecuária exclusivamente.

\section{REFERÊNCIAS}

CARNEIRO, M. J. Agricultores familiares e pluriatividade: tipologias e políticas. In: CARVALHO COSTA, L.F.; MOREIRA, R.J.; BRUNO, R. (org.). Mundo Rural e Tempo Presente. Rio de Janeiro: Mauad, p. 325-344, 1999.

DUFUMIER, M. Importancia de la tipología de unidades de producción agrícolas en el análisis de diagnostico de realidades agrarias. In: ESCOBAR, G.; J. BERDEGUÉ (Eds). Tipificación de Sistemas de Producción Agrícola. Red Internacional de Metodología de Investigación de Sistemas de Producción (RIMISP), Santiago-Chile, 1990.

DUFUMIER, M. Projetos de Desenvolvimento Agrícola: manual para especialistas. [tradução de Vitor De Athayde Couto]. Salvador: EDUFBA, 2007.

GARCIA FILHO, D. P. Análise e diagnóstico de sistemas agrários. Guia metodológico. INCRA/FAO, 1999.

GLEBER, L. Redução de Riscos de Impacto Ambiental na Produção Integrada de Maçãs. Circular Técnica 38. Ministério da Agricultura, 
Pecuária e Abastecimento. Empresa Brasileira de Pesquisa Agropecuária. Bento Gonçalves, RS, 2002.

INSTITUTO BRASILEIRO DE GEOGRAFIA E ESTATÍSTICA. IBGE Cidades Dados básicos por município. 2010. Disponível em: <http://www.ibge.go v.br/cidade sat/painel/painel.php?codmun=432250\#>. Acesso em: 05 mar 2013.

LIMA, A. J. P. de. et al. Administração da unidade de produção familiar: modalidades de trabalhos com agricultores. Ijuí: UNIJUÍ, 1995.

MAZOYER, M.; ROUDART L. História das agriculturas no mundo: do neolítico à crise contemporânea. [tradução de Cláudia F. Falluh Balduino Ferreira]. São Paulo: Editora UNESP; Brasília, DF: NEAD, 2010.

MENEZES, D. J. Mapa de localização do Município de Vacaria/RS. Material não publicado. Santa Maria, 2013.

MENEZES, D. J. Mapa geomorfológico de Vacaria/RS. Material não publicado. Santa Maria, 2013.

MENEZES, D. J. Mapa hidrográfico de Vacaria/RS. Material não publicado. Santa Maria, 2013.

MENEZES, D. J. Mapa de uso do solo da microrregião central do Município de Vacaria/RS, incluindo o $1^{\circ}, 2^{\circ}, 3^{\circ}$ e $6^{\circ}$ Distritos. Material não publicado. Santa Maria, 2013.

NEUMANN, P. S.; FIALHO, M. A. V. Sistemas Agrários. Apostila do curso de Graduação Tecnológica em Agricultura Familiar e Sustentabilidade. Santa Maria: CCR/EaD, 2009.

PLANO DE DESENVOLVIMENTO DA REGIÃO DOS CAMPOS DE CIMA DA SERRA. Relatório final - Corede Campos de Cima da Serra. Vacaria, RS:2010. 
Filipe A. Xavier Lima, Gustavo D. Benítez Castro, Rodrigo Gisler Maciel, Pedro Selvino

PLANO AMBIENTAL MUNICIPAL. Plano Ambiental municipal - Versão para o COMDEMA. Vacaria, RS: 2006.

QUEIROZ, T. R. Sistema de custeio e indicadores de desempenho para a agricultura familiar. 2004. 140p. Dissertação (Mestrado em Engenharia de Produção) - Departamento de Engenharia de Produção, Universidade Federal de São Carlos, São Carlos, 2004.

SILVA NETO, B.; BASSO, D. (Orgs.). Sistemas Agrários do Rio Grande do Sul Análise e Recomendações de Políticas. Ijuí/RS: Ed. UNIJUÍ, 2005.

SOUZA R. de et al. A administração da fazenda. São Paulo: Globo, 1992.

Submetido em 25/09/2014

Aprovado em 30/10/2015

\section{Sobre os autores}

\section{Filipe Augusto Xavier Lima}

Doutorando do Programa de Pós-Graduação em Extensão Rural da Universidade Federal de Santa Maria (PPGExR, UFSM). Professor substituto da Universidade Federal Rural de Pernambuco (UFRPE).

E-mail: filipeaxlima@hotmail.com

\section{Gustavo Daniel Benítez Castro}

Mestre em Extensão Rural do Programa de Pós-Graduação em Extensão Rural da Universidade Federal de Santa Maria (PPGExR, UFSM). Professor das Áreas de Economia e Administração da Universidad De La República-UY.

E-mail: g.benitezcastro@gmail.com

\section{Rodrigo Gisler Maciel}

Mestrando em Extensão Rural do Programa de Pós-Graduação em Extensão Rural da Universidade Federal de Santa Maria (PPGExR, UFSM). Professor substituto da Universidade Federal do Pampa (UNIPAMPA).

E-mail: rodrigo.gisler@gmail.com

\section{Pedro Selvino Neumann}

Professor do Programa de Pós-Graduação em Extensão Rural da Universidade Federal de Santa Maria (PPGExR, UFSM).

E-mail: psneumann@smail.ufsm.br 